\title{
High HIV sero-prevalence and associated sexual behavioral risk factors among university students in Southeast Nigeria: our experiences from on-campus voluntary counselling and testing centers
}

\author{
Kelechi M. Nworie, Ikenna C. Ugwuoke \\ Pharmaceutical Outcomes Research Group, Faculty of Pharmacy, University of Nigeria, Nsukka, Nigeria
}

\begin{abstract}
Introduction: The global rate of human immunodeficiency virus (HIV) prevalence among youths and adolescents is increasingly alarming, and sexual behavior still remains the major determinants in the spread of the disease. However, the objective of this study is to evaluate HIV sero-prevalence and associated sexual risk factors among undergraduate students, as a model to aid HIV sensitization, prevention, and intervention strategies in Nigeria.

Material and methods: A cross-sectional study was conducted among 670 undergraduate students aged 15-26 years of the University of Nigeria Nsukka, using well-structured questionnaires to obtain demographic and sexual behavioral data. Enzyme-based immunoassay technique was used by Voluntary Counselling and Testing (VCT) centers located in the institution to confirm HIV sero-status.

Results: The overall prevalence of HIV among undergraduate students was relatively high 5.2\% against the recent national estimation. The participants had an existence of increased sexuality, which encompasses multiple sex partnering and high frequency of sex in a short period of 6 months. HIV prevalence among female students $(6.5 \%)$ was not statistically significant at $p<0.05$, when compared with their male counterpart (4.3\%).

Conclusions: The results and observations on this study emphasize an urgent need for adoption of effective HIV/acquired immune deficiency syndrome (AIDS) intervention programs targeted at the general young individuals in Nigeria. Therefore, we find it crucial for the introduction of sexual health education into the school curriculum aimed at educating young individuals to adopt a healthy living.
\end{abstract}

HIV AIDS Rev 2018; 17, 3: 203-209

DOI: https://doi.org/10.5114/hivar.2018.78493

Key words: HIV, Nigeria, health-related quality of life, students, counselling.

\section{Introduction}

Human immunodeficiency virus (HIV) is considered a pandemic disease. It has a great impact on society, both as an illness and as a source of discrimination [1]. In 2015, about 36.7 million people were living with HIV (most of those infected live in Sub-Saharan Africa) and resulted in about 1.1 million deaths [2]. HIV is an infectious disease and
Address for correspondence: Kelechi M. Nworie, Pharmaceutical Outcomes Research Group, Faculty of Pharmacy, University of Nigeria, Nsukka, 410001 Nsukka, Nigeria, phone: $+234(0) 8063718781$,

e-mail: nworiekelechimartins@gmail.com
Article history:

Received: 04.08.2017

Received in revised form: 31.01.2018

Accepted: 12.02.2018

Available online: 15.08 .2018
International Journal of HIV-Related Problems

HIV \& AIDS

R e v i e w 
is transmitted primarily by unprotected sex, contaminated blood transfusion, hypodermic needles, delivery (mother to unborn child), and breastfeeding. Early diagnosis and knowledge of one's HIV status is one of the major warheads for combating and preventing the virus especially in the sub-Saharan Africa. In addition, proper clinical awareness and counselling helps to reduce the spread of the infection among individuals.

Recent findings have shown that new cases of HIV infections commonly occur in individuals under the age of 25 , and that $8 \%$ of these cases worldwide occurs in youths within the age of 15-24 years old [3]. This is exactly the age bracket of most Nigerian undergraduate students; hence, youths are especially more exposed to contracting the disease. Therefore, a logical approach of controlling and preventing HIV may be suggested to target this group of individuals as an important strategy. Ironically, in spite of all efforts of awareness and promotion aimed at decreasing the spread of the disease among people living in Sub-Saharan Africa [4], there has not been an appreciable improvement.

Among other aspects, belief, economic, and socio-cultural factors are also believed to be reasons affecting predominant vulnerability of undergraduate students to HIV infection. Also, a study noted the perception difference of the infection between male and female students [5]. Furthermore, the location of higher institutions in Nigeria is also a contributing factor to spread of the disease among students [6]. Most tertiary institutions are located in rural regions, and $70 \%$ of the students live off campus. This is a major concern as interaction (especially through sexual intercourse) between students and rural dwellers living with HIV is greatly influenced. Social interactions between students and people living with HIV in communities where tertiary institutions are located, may affect the infection rate of HIV positively [6]. However, reports have acknowledged that there is a vast ignorance and neglect even of the existence of the disease in tertiary institutions of Sub-Saharan Africa [7].

Voluntary counselling and testing (VCT) are when a person chooses to undergo HIV counselling, so that they make an informed decision about whether to be tested for HIV. VCT is a strategy set up by governments and NGOs to help citizens acknowledge their sero-status and lessen the amount of stigma associated with the test. Moreover, if individual discover earlier that they are positive, they can easily get information and counselling on how to live a normal life with the virus, seek emotional support, and get access to drugs. Nigeria is one the countries with high HIV prevalence over 4\%; despite this challenge, the patronage of VCT centers is relatively very low [8]. Therefore, in recent years, different and simpler modalities of VCT centers have been implemented including mobile-and home-based testing and counselling to solve this problem [9].

In the Nigerian population, undergraduate students are most vulnerable to HIV infections, and there is lots of valuable information on documentation of these facts. In this study, the authors provided data on HIV sero-prevalence and sexual lifestyle associated with this rate among undergraduate students in a tertiary institution in Southeast Nigeria.

\section{Material and methods}

\section{Study population and eligibility}

The cross-sectional study was conducted at five mobileon-campus VCT centers in the University of Nigeria, Nsukka (UNN) located in South-Eastern Nigeria, and included students who voluntarily came to these centers for HIV counselling and testing. The services rendered to students by the VCT centers including distribution of male condoms are without charge, and were sponsored by the National Agency for the Control of AIDS (NACA). To ensure the sample was unbiased, simple random sampling design was adopted for obtaining representative samples. Both male and female residential students aged 15-26 years were included in the study after formerly obtaining their consent according to the Nigerian National Ethics and operational guidelines for research on human subjects. Eligibility included students who were tested and agreed to take part in an administered questionnaire.

\section{Questionnaire and data collection}

The study tool for interview was a carefully designed, tested, self-structured questionnaire aimed at meeting the criteria and purpose of the study. The questionnaire was developed based on a previously used design in another study [10], with little suitable modification. The reliability of the questionnaire was ascertained by conducting a pilot study using 20 participants. The study was conducted between May and July 2017. The questionnaire was administered face-to-face to all participants at the VCT centers before the test, and retrieved immediately by the investigators after been carefully completed.

\section{Blood sample evaluation protocol and testing}

The health technicians collected blood samples from each participant after ascertaining their knowledge on HIV. Blood samples were collected after cleaning the thumb with alcohol-soaked cotton wool and piercing it with sterile lancet supplied along with the HIV test kit. The test was performed using the anti-HIV Uni-Gold test kit (manufactured by Trinity Biotechnology PLC, IDA Business Park, Bray Coy Wicklow, Ireland). The test is a rapid immune-assay based on the chromatographic sandwich principle. The health technicians immediately conferred the students their test result in absolute confidentiality after the test. Students who confirmed positive were also subsequently recommended to heart-to-heart centers, located near the institution for further care, treatment, and counselling. 


\section{Ethical clearance}

A letter was given to each VCT center present in the institution, requesting their assistance to conduct the study by releasing any necessary information relevant to particular aspect of the study. An interactive session was held between the researchers and the health personnel, and thereafter approval was obtained. The study was also subjected to institutional ethics review and clearance was obtained from the University of Nigeria Nsukka after careful consideration.

\section{Data analysis}

Categorical variables were expressed as frequency (percentage) and continuous variables as mean $( \pm$ SD). Statistically significant was considered at a value of $p<0.05$. The relationship between the prevalence of HIV infection and various sexual behavioral risk factors was evaluated by calculating an odd ratio (OR) at $95 \%$ confidence interval (CI).

\section{Results}

\section{Socio-demographics}

The socio-demographical distribution of participants is shown in Table 1. A total of 670 participants were identified for the study. The majority age group was $18-20$ years (37.2\%), probably consisting of students in their second or third level in school, while the least age group was 24-26 years (13.6\%). The participants also consisted of 376 (56.1\%) males and $294(43.9 \%)$ females. Most of the participants $(619,92.4 \%)$ were single, 43 (6.4\%) were married, and only 8 (1.2\%) reported cases of separation or divorce. Majority were Christians 640 (95.5\%). Moslems and Pagans were few, $20(3.0 \%)$ and $10(1.5 \%)$, respectively.

\section{HIV sero-prevalence}

Table 2 indicates the distribution of HIV prevalence across the different age groups and gender. The overall prevalence of HIV in UNN students was $5.2 \%$, where the prevalence among females and males was $6.5 \%$ and $4.3 \%$, respectively. This equally shows that HIV prevalence among female students is higher as compared to male students. Age-and sex-specific sero-prevalence of HIV shows that prevalence
Table 1. Socio-demographic distribution of participants

\begin{tabular}{|c|c|c|}
\hline Characteristics & Frequency (f) & Percentage (\%) \\
\hline Age (years) & $n=670$ & \\
\hline $15-17$ & 230 & 34.3 \\
\hline $18-20$ & 249 & 37.2 \\
\hline $21-23$ & 100 & 14.9 \\
\hline $24-26$ & 91 & 13.6 \\
\hline Mean \pm SD & $19.23 \pm 3.05$ & \\
\hline \multicolumn{3}{|l|}{ Sex } \\
\hline Male & 376 & 56.1 \\
\hline Female & 294 & 43.9 \\
\hline \multicolumn{3}{|l|}{ Marital status } \\
\hline Single & 619 & 92.4 \\
\hline Married & 43 & 6.4 \\
\hline Divorced/separated & 8 & 1.2 \\
\hline \multicolumn{3}{|l|}{ Religion } \\
\hline Christianity & 640 & 95.5 \\
\hline Islam & 20 & 3.0 \\
\hline Pagan (African tradition) & 10 & 1.5 \\
\hline \multicolumn{3}{|l|}{ Ethnicity } \\
\hline Igbo & 425 & 63.4 \\
\hline Yoruba & 197 & 29.4 \\
\hline Hausa & 48 & 7.2 \\
\hline \multicolumn{3}{|l|}{ Residence } \\
\hline On-campus & 474 & 70.8 \\
\hline Off-campus & 196 & 29.2 \\
\hline
\end{tabular}

among students aged $15-17$ years is $3.4 \%$ and $2.7 \%$ for female and male students, respectively. The prevalence in students aged 18-20 years old was higher than that recorded in students aged $15-17$ years old at $7.9 \%$ and $3.8 \%$ for female and male students, respectively. Prevalence in male students aged $21-23$ and $24-26$ years old was $7.1 \%$ and $6.3 \%$, respectively. The highest prevalence in students across all ages and sex was recorded among females aged 24-26 years old, at $11.6 \%$. Except for ages 21-23, at which prevalence of males (7.1\%) was higher than females (6.8\%), prevalence in females was higher than males across all ages.

Table 2. HIV sero-prevalence of participants by age group and sex

\begin{tabular}{l|c|c|c|c|c|c|c|c}
\hline \multirow{2}{*}{ Age (years) } & \multicolumn{2}{|c|}{ Positive result $(n)$} & \multicolumn{2}{c|}{ Prevalent rate $(\%)$} & \multicolumn{2}{c|}{ Number tested } & \multicolumn{2}{c}{ Total } \\
\cline { 2 - 9 } & Males & Females & Males & Females & Males & Females & Prevalent rate (\%) & Number tested $(n)$ \\
\hline $15-17$ & 3 & 4 & 2.7 & 3.4 & 112 & 118 & 3.0 & 230 \\
\hline $18-20$ & 6 & 7 & 3.8 & 7.9 & 160 & 89 & 5.2 & 249 \\
\hline $21-23$ & 4 & 3 & 7.1 & 6.8 & 56 & 44 & 7.0 & 100 \\
\hline $24-26$ & 3 & 5 & 6.3 & 11.6 & 48 & 43 & 8.8 & 91 \\
\hline Total & 16 & 19 & 4.3 & 6.5 & 376 & 294 & 5.2 & 670 \\
\hline
\end{tabular}




\section{Sexual behavioral pattern}

Table 3 represents the sexual behavioral distribution of the participants, which indicates that 573 (85.5\%) have had sex, while 97 (14.5\%) have not. Age of first-time sex occurred mostly within the ages of 11-15 years, 157 (27.4\%), and 16-20 years, 337 (58.8\%). First-time sex 10 (1.7\%) also occurred within the age range of 1-5 years.

Table 3. Sexual behavioral distribution of participants

\begin{tabular}{|c|c|c|}
\hline Characteristics & Frequency & Percentage (\%) \\
\hline Ever had sex\# & $n=670$ & \\
\hline Yes & 573 & 85.5 \\
\hline No & 97 & 14.5 \\
\hline Age of first sex (years) & $n=573$ & \\
\hline $1-5$ & 10 & 1.7 \\
\hline $6-10$ & 44 & 7.7 \\
\hline $11-15$ & 157 & 27.4 \\
\hline $16-20$ & 337 & 58.8 \\
\hline $21-25$ & 25 & 4.4 \\
\hline Mean \pm SD & $15.82 \pm 3.85$ & \\
\hline \multicolumn{3}{|l|}{ Sexually active ${ }^{*}$} \\
\hline Yes & 524 & 91.5 \\
\hline No & 49 & 8.5 \\
\hline Sex partners in past 12 months & $n=524$ & \\
\hline Only 1 & 168 & 32.1 \\
\hline $2-5$ & 215 & 41.0 \\
\hline $6-10$ & 83 & 15.8 \\
\hline$>10$ & 58 & 11.1 \\
\hline \multicolumn{3}{|l|}{ Protected sex always } \\
\hline Yes & 279 & 53.2 \\
\hline No & 245 & 46.8 \\
\hline \multicolumn{3}{|l|}{ Had sex in last 6 months } \\
\hline Yes & 425 & 81.1 \\
\hline No & 99 & 18.9 \\
\hline Amount of sex in last 6 months & $n=425$ & \\
\hline Only 1 & 22 & 5.2 \\
\hline $2-5$ & 108 & 25.4 \\
\hline $6-10$ & 190 & 44.7 \\
\hline$>10$ & 105 & 24.7 \\
\hline \multicolumn{3}{|l|}{ Reason of sex in last 6 months } \\
\hline For procreation & 8 & 1.9 \\
\hline For pleasure & 319 & 75.1 \\
\hline For money & 30 & 7.1 \\
\hline To please somebody & 38 & 8.9 \\
\hline To obtain favor & 12 & 2.8 \\
\hline To express love & 18 & 4.2 \\
\hline
\end{tabular}

"Sex was defined as vaginal or anal heterosexual intercourse.

${ }^{*} \mathrm{Had}$ sexual intercourse within the last 30 days preceding the survey
The results indicate that within the last 12 months, $168(32.1 \%)$ of the participants had only one sex partners, $215(41.0 \%)$ had $2-5$ partners, and as high as $83(15.8 \%)$ and 58 (11.1\%) had 6-10 and more than 10 partners, respectively. Apparently, $425(81.1 \%)$ had sex in the last 6 months and 279 (53.2\%) claimed to have ensured protected sex during this period. High proportion of the participants, 190 (44.7\%) and 105 (24.7\%) had sex 6-10 times, and more than 10 times, respectively, within the last 6 months.

Table 3 also shows the reason for sex by participants. These reasons include: for procreation 8 (1.9\%), for pleasure $319(75.1 \%)$, for money $30(7.1 \%)$, to please somebody $38(8.9 \%)$, to obtain favor $12(2.8 \%)$, and to express love $18(4.2 \%)$. Most of the participants, 319 (75.1\%) indulged in sex for pleasure.

\section{Association between HIV sero-prevalence and reported sexual behavioral distribution}

Table 4 shows that students who had sex before age 16 years (OR: 2.54; CI: 1.02-6.28), students who were not

Table 4. Association between human immunodeficiency virus (HIV) prevalence and reported sexual behavioral pattern among participants

\begin{tabular}{|c|c|c|}
\hline Characteristics & OR & $95 \% \mathrm{Cl}$ \\
\hline \multicolumn{3}{|l|}{ Ever had sex" } \\
\hline Yes & 1.33 & $0.46-3.86$ \\
\hline No & 1.00 & \\
\hline \multicolumn{3}{|l|}{ Age of first sex } \\
\hline No sex before age 16 years & 1.00 & $1.02-6.28^{*}$ \\
\hline Had sex before age 16 years & 2.54 & \\
\hline \multicolumn{3}{|l|}{ Sexually active ${ }^{*}$} \\
\hline No & 0.46 & $0.17-1.26$ \\
\hline Yes & 1.00 & \\
\hline
\end{tabular}

Protected sex always

\begin{tabular}{l|l|l}
\hline No & 1.00 & $0.21-1.15$ \\
\hline Yes & 0.49 & \\
\hline
\end{tabular}

Had $>5$ partners in past 12 months

\begin{tabular}{l|l|l}
\hline Yes & 2.45 & $1.11-5.44^{\star}$ \\
\hline No & 1.00 & \\
\hline
\end{tabular}

Had sex in last 6 months

\begin{tabular}{l|l|l}
\hline No & 0.10 & $0.05-0.24^{\star *}$ \\
\hline Yes & 1.00 & \\
\hline
\end{tabular}

Had sex $>10$ times in last 6 month

\begin{tabular}{l|l|l}
\hline Yes & 1.54 & $0.38-6.27$ \\
\hline No & 1.00 & \\
\hline
\end{tabular}

"Sex was defined as vaginal or anal heterosexual intercourse. *Had sexual intercourse within the last 30 days preceding the survey. ${ }^{* *} p<0.0001 ;{ }^{*} p<0.05$

$O R$ - odd ratio, $\mathrm{Cl}$ - confidence interval 
virgin (OR: 1.33; CI: 0.46-3.86), those who had more than 5 partners in past 12 months (OR: 2.45; CI: 1.11-5.44), and those involved in sex more than 10 times in past 6 months (OR: 1.54; CI: 0.38-6.27) were more likely of getting infected with HIV/AIDS. However, students who did not have sex in past 6 month (OR: 0.10; CI: 0.05-0.24) were less likely of getting infected with HIV/AIDS. Also, students who are not sexually active (OR: 0.46 ; CI: $0.17-1.26)$ and students who always have protected sex (OR: 0.49 ; CI: $0.21-1.15$ ) were less likely of getting infected with HIV/AIDS.

\section{Discussion}

Due to the increasing number of youths in developing countries, sexual behavioral study of young people especially between the ages of 15-26 years, is important because it plays a major role in the trajectory of AIDS pandemic [6]. Recently, many authors are expanding studies of sexuality by offering crucial quantitative and qualitative reports about sexuality. Efforts also are being made to expand international studies of sexual behavior [11], and most authors agree that HIV/AIDS epidemic has been the major impulse towards this development. While so much has been learned about association between HIV prevalence and sexual behavior in recent decades, this research has focused on young people in tertiary institutions who are most bound by limitless degree of sexual freedom. There have been continuous and increasing efforts on awareness and campaigns about the risk of unprotected sexuality directed to the general public in most developing countries. However, this has yielded a less corresponding improvement as evidenced by relatively high HIV prevalence rate and high-risk sexual behavior experienced among Nigerian youths.

Data on HIV prevalence in a tertiary institution was obtained from 670 students at five VCT centers located in the University of Nigeria, Nsukka. The overall prevalence rate at this institution was $5.2 \%$. This rate is significantly higher than the national data, which estimates that $4.2 \%$ of young people (ages, 15-24 years) are living with HIV [12]. According to this report, prevalence in males and females was highest among ages 21-23 years and 24-26 years, respectively, while students aged 15-17 years old had the lowest prevalence for both males and females. This pattern shows that age and gender inequality is important in HIV epidemic study. Prevalence in females (6.5\%) was observed to be generally higher than males $(4.3 \%)$. This result agrees with the gender differences of HIV prevalent reports $[13,14]$ in other African countries. Even though there was a complementary rise and drop in 21-23 years, resulting to the prevalence of males (7.1\%) being higher than females (6.8\%), prevalence was still higher among females (11.6\%) than males $(6.3 \%)$ in the next age group. Increased HIV infection among female students may be attributed to a number of factors namely, knowledge and awareness of STDs, increased sexual activity, high-rate of unprotected sex, frequent casual sex with multiple partners (older) especially those that have been widely exposed with resultant high-risk of the STD infection, and other sexually abusive activities e.g., rape $[15,16]$.

Fresher undergraduates especially those living in urban areas experience a restricted freedom to sexual expression at their various homes before arriving on campus. As a result, they tend to be more excited and anxious about an active sexual experience upon arrival on campus [17]. This makes them vulnerable to infection. Therefore, there is a need to guide and support these set of students especially girls on HIV knowledge and awareness during their first few months on campus [18]. We observed that male students were more sexually active and had a greater number of sexual intercourses in the last 6 months than their female counterpart. However, this did not manifest as higher prevalence in males than females. This can be due to the fact that awareness of HIV prevention is higher in males than females. In the 2013, in a national demographic and health survey (the most recent available), 70\% of young males aged $15-24$ years were aware that using condom can reduce the risk of STD transmission compared to $56 \%$ of their female peers [19]. Several other reports also noted high HIV prevalence among undergraduates in other African countries [20,21]. The data from these authors also strongly suggests a clear and profound evaluation for initiation of HIV control programs targeted at student in tertiary institutions. Studies have shown that male students are more HIV-aware than their female counterpart, and this has the implication that females need to be empowered more on HIV/AIDS knowledge to help control the disease in the society [23].

The fact remains that gender difference is crucial in HIV assessment of a population. Although, gender differences by some studies on adolescent's HIV/AIDS knowledge showed no gender differences [24-26]. However, in contrast, this did not confirm as many other reports have noted gender differences in HIV knowledge and awareness among adolescents. A study carried on university adolescents in Zimbabwe reported that men claimed having the right of decision in the use condoms during intercourse [27]. Another study reported that gender differences in favor of males can be directed to: poor education among females, dependency on men and other socio-cultural barrier, all of which contribute to the slope knowledge of HIV/AIDS among young women [28]. Although our study observed higher prevalence in females, which may be attributed to poor knowledge and awareness, it should be noted that some studies have held this not to be true. For instance, a gender differences study among university adolescents in Afghanistan observed female students to be more knowledgeable than their male counterpart [29]. Also, another study among university students in Turkey observed that female students performed better in a question/statement-based HIV knowledge assessment.

According to the 2013 Nigeria National Demographic and Health Survey (NDHS), $48.9 \%$ of adolescents are sexually active [30]. However, our study shows 524 (91.5\%) sexually active participants. It is distressing to note that only an average $279(53.2 \%)$ always ensure protected sex. Surpris- 
ingly, $83(15.8 \%)$ and $58(11.1 \%)$ of these sexually active participants in the last twelve months had 6-10 and more than 10 partners, respectively. The reason for this increased sexuality among students may partly be attributed to the freedom of sexual life without close guidance, or the excitement of sexual experimentation without considering the consequences. A more distressing observation is the elevated number of respondents 319 (75.1\%) who indulge in sex for pleasure. Different studies have also reported multiple sexual partnering among adolescents and youths in different regions of Nigeria [31-33]. One of the high-risk behaviors that expose an individual to HIV infection is multiple sex partnering. This is even more conspicuous among undergraduate students, considering their high sexuality with relatively low sex protection $[34,35]$.

Furthermore, availability of VCT centers in Nigerian tertiary institutions is also as important as its awareness among students. The turn-out by male students for VCT recorded by this study does not confirm with the observation in another study [36]. However, this study was assessed on a basis of willingness to pay for VCT, considering the financial challenges of students. Awareness of VCT centers was found to be moderately good among both genders. It is also possible that there are also some students who are still ignorant of VCT centers and services. Therefore, more of free-access VCT centers should be created and widely publicized not in tertiary institutions alone, but also in various communities.

\section{Conclusions}

This study observed an increased rate of HIV sero-prevalence among undergraduate students. In light of this, intervention programs directed to youths should exist in the Nigerian HIV/AIDS prevention and control strategy. Such programs should involve integrating sexuality education as a comprehensive part of our health advocacy program targeted at tertiary institutions in Nigeria as well as secondary schools. This need has become critical and urgent. These advocacy programs should entirely explore youth orientation at every level of our education; harness it, thereby using it to scheme up reproductive health enlightenments through class lectures, print media, and social media. Public awareness campaigns tailored to encourage and promote the use of condoms as an effective part of safe sex practice for the prevention of HIV infection is highly recommended. National health planners should endeavor to ensure a favorable environment for the process of condom use. This may include maintaining favorable legislation for importers and marketers, and ensuring good basic marketing concepts such as advertising, good quality products, effective nationwide distribution, and cost-effectiveness of condoms. Also, clinical services such as STI case management approaches for symptomatic patients, screening for asymptomatic infections, and sex partner management strategies should be assisted by relevant efforts to educate, counsel, and provide the means for STI prevention on a nationwide scale. Undoubtedly, there is an urgent need to monitor and control the situation of HIV infection among tertiary institution on a regular basis. Anything short of this puts us on the on the peril of a massive encroachment of this disease, which has already claimed countless lives in Africa.

\section{Acknowledgement}

The authors would like to thank the University of $\mathrm{Ni}$ geria Nsukka for approving this study. We also express our thanks and gratitude to all students of the University of Nigeria Nsukka who volunteered to participate in the study.

\section{Conflict of interest}

The authors declare no potential conflicts of interest with respect to the research, authorship, and/or publication of this article.

\section{References}

1. Oramasionwu CU, Daniels KR, Labreche MJ, Frei CR. The Environmental and Social Influences of HIV/AIDS in Sub-Saharan Africa: A Focus on Rural Communities. Int J Environ Res Public Health 2011; 8: 2967-2979.

2. WHO, 2015. Fact Sheet on HIV/AIDS. Available at: http://www. who.int/entity/mediacenter/factsheets/fs360/en/

3. Mukoma W, Flisher AJ, Ahmed N, et al. Process evaluation of a school-based HIV/AIDS intervention in South Africa. Scand J Public Health 2009; 37: 37-47.

4. WHO. Global AIDS Surveillance - part 1. Wkly Epidemiol Rec 2017; 72: 357-358.

5. Ebeniro CD. Knowledge and beliefs about HIV/AIDS among male and female students of Nigerian Universities. J Comp Res Anthropol 2010; 1: 121-131.

6. Emeka-Nwabunnia I, Ibeh BO, Ogbulie TO. High HIV sero-prevalence among students of higher education in Southeast Nigeria. Asian Pac J Trop Dis 2014; 4: 159-165.

7. Kelly MJ. The significance of HIV/AIDS for universities in Africa. J High Educ Afr 2003; 1: 1-23.

8. Yahaya LA, Jimoh AA, Balogun OR. Factors Hindering Acceptance of HIV/AIDS Voluntary Counseling and Testing (VCT) among Youth in Kwara State, Nigeria. Afr J Reprod Health 2010; 14: 159-164.

9. Fonner VA, Denison J, Kennedy CE, et al. Voluntary counseling and testing (VCT) for changing HIV-related risk behavior in developing countries (review). Cochrane Database Syst Rev 2012; doi: 10.1002/14651858.CD001224.pub4.

10. Adinma JIB, Osita U, Adinma DE, Nkemakolam E. Sexual behaviour among students in a tertiary educational institution in south eastern Nigeria. Adv Reprod Sci 2016; 4: 87-92.

11. Parker R. International perspectives on sexuality research. In: Bancroft J (ed.). Researching Sexual Behavior: Methodological issues. Indiana University Press, Bloomington 1997; 9-36.

12. The Avert. Available at: https://www.avert.org/professionals/hivaround-world/sub-saharan-africa/nigeria.

13. Kenya National Bureau of Statistics (KNBS) and ICF Macro. Kenya Demographic and Health Survey 2008-09. KNBS and ICF Macro. 2010. Calverton, Maryland, USA. Available at: http://dhsprogram. com/pubs/pdf/FR229.pdf.

14. White HL, Kristensen S, Coulibaly DM, et al. Prevalence and predictors of HIV infections amongst Malian students. AIDS Care 2009; 21: 701-707.

15. Adamson SM. HIV infection and AIDS among young women in South Africa. Croat Med J 2008; 49: 423-435. 
16. Rakesh KS, Shraboni P. What factors are responsible for high prevalence of HIV infection among urban women than rural women in Tanzania? Ethiop J Health Sci 2015; 25: 321-328.

17. Owusu GA, Tawiah MA, Sena-Kpeglo C, Onyame JT. Orientation impact on performance of undergraduate students in University of Cape Coast (Ghana). Int J Educ Admin Pol Stud 2014; 6: 131-140.

18. Asante KO, Oti-Boadi M. HIV/AIDS knowledge among undergraduate university students: implications for health education programs in Ghana. Afr Health Sci 2013; 13: 270-277.

19. National Population Commission (NPC) Nigeria \& ICF International. Nigeria Demographic and Health Survey 2013. 2014. Abuja, Nigeria: NPC Nigeria \& ICF International. Available at: http:// dhsprogram.com/pubs/pdf/FR293/FR293.pdf.

20. Nel A, Mabude Z, Smith J, et al. HIV Incidence Remains High in KwaZulu-Natal, South Africa: Evidence from Three Districts. PLoS One 2012; 7: e35278.

21. Karim QA, Kharsany AB, Frohlich JA, et al. Stabilizing HIV prevalence masks high HIV incidence rates amongst rural and urban women in KwaZulu-Natal, South Africa. Int J Epidemiol 2011; 40: 922-930.

22. Othieno CJ, Okoth R, Peltzer K, et al. Risky HIV sexual behaviour and depression among University of Nairobi students. Ann Gen Psychiatry 2015; 14.

23. Mwamwenda TS. African University Students' Gender Differences in HIV/AIDS Knowledge. Med J Soc Sci 2014; 5: 432-437.

24. Ugboma HA, Kooffreh ME, Nwauche CA. Gender differences in students' knowledge of HIV/AIDS in the Niger Delta, Nigeria. J Clin Med Res 2011; 3: 20-22.

25. Mudinngayi A, Lutala P, Mupenda B. HIV knowledge and sexual risk behaviour among street adolescents in rehabilitation centers in Kinshasa; DRC: gender differences. Pan Afr Med J 2011; 10: 23.

26. Ojo FY. An assessment of HIV/AIDS knowledge and risk behaviour of fresh undergraduates of tertiary institutions in Ekiti-State, Nigeria. Eur J Hum Soc Sci 2011; 9: 379-387.

27. Terry PE, Mhloyi M, Masvaure TB, Adlis S. Gender equity and HIV/ AIDS prevention: comparing gender differences in sexual practice and beliefs among Zimbabwe university students. Int Q Community Health Educ 2005; 24: 29-43.

28. Burgoyne AD, Drummond PD. Knowledge of HIV and AIDS in women in sub-Saharan Africa. Afr J Reprod Health 2008; 12: 14-31.

29. Mansoor AB, Fungladda W, Kaewkungwal J, Wongwit W. Gender differences in KAP related to HIV/AIDS among freshmen in Afghan Universities. Southeast Asia J Trop Med Public Health 2008; 39: 404-418.

30. National Population Commission (NPC) Nigeria \& ICF Macro, 2009. Nigeria Demographics and Health Survey 2008. Abuja, Nigeria: NPC Nigeria \& ICF Macro. Available at: http://dhsprogram. com/pubs/pdf/FR222/FR222.pdf.

31. Kabir M, Iliyasu Z, Abubakar IS, Kabir AS. Sexual behaviour among students in tertiary institutions in Kano, Northern Nigeria. J Commun Med Prim Health Care 2004; 16: 17-22.

32. Sabitu K, Illiyasu Z, Baba SE. Sexual behaviour and predictors of condom use among students of a Nigerian tertiary institution. Niger J Med 2007; 16: 338-343.

33. Owoaje ET, Uchendu OC. Sexual risk behaviour of street youths in south west Nigeria. East Afr J Public Health 2009; 6: 274-279.

34. Adinma JIB, Agbai AO, Okeke AO, Okaro JM. Contraception in teenage in Nigerian school girls. Advances in Contraception 1999; 15: 283-291.

35. Adinma J, Okeke AO. Contraception: awareness and practice amongst Nigerian tertiary school girls. West Afr J Med 1995; 14: 34-38.

36. Uzochukwu B, Uguru N, Ezeoke U, et al. Voluntary counselling and testing (VCT) for HIV/AIDS: a study of the knowledge, awareness and willingness to pay for VCT among students in tertiary institutions in Enugu State Nigeria. Health Policy 2011; 99: 277-284. 